\title{
O SENTIDO DE FILOSOFIA NO AGOSTINHO DE CASSICÍACO
}

\author{
The Sense of Philosophy in Augustine of Cassiciaco
}

Émilien Vilas Boas Reis ${ }^{1}$

\begin{abstract}
RESUMO: Este artigo trata do entendimento de Agostinho a respeito da filosofia, sua finalidade e sentido, após sua conversão ao cristianismo em 386 . O texto contextualiza sua adesão à filosofia, a partir da leitura do Hortensius, de Cícero, e de como ele reinterpretará a filosofia à luz do cristianismo. Para tanto, serão utilizadas como referências as obras Contra Academicos e De Beata Vita, diálogos escritos em Cassicíaco antes do seu batismo, em abril de 387. O artigo tenciona mostrar como Agostinho parte de um arcabouço intelectual do pensamento antigo para ir além dele através de sua adesão ao cristianismo; assim, ele faz com que a filosofia seja pensada como filosofia cristã. A pesquisa tem metodologia qualitativa a partir de uma análise bibliográfica de textos agostinianos, bem como do uso de bibliografia secundária.
\end{abstract}

PALAVRAS-CHAVE: Santo Agostinho; Filosofia; Felicidade; Deus; Cassicíaco.

ABSTRACT: This paper is about Augustine's understanding of philosophy, its purpose and meaning, after his conversion to Christianity in 386. The text contextualizes his adherence to philosophy, from the reading of Cicero's Hortensius, and how he will reinterpret the philosophy in the light of Christianity. For this purpose, the works Contra Academicos and De Beata Vita, dialogues written in Cassiciaco before his baptism, in April 387, will be used as references. The paper intends to show how Augustine starts from the ideas of ancient thought and how he goes beyond it through his adherence to Christianity. Thus, he turns philosophy into Christian philosophy. The research has a qualitative methodology, based on a bibliographic analysis of Augustinian texts, as well as the use of secondary bibliography.

KEYWORDS: Saint Augustine; Philosophy; Happiness; God; Cassiciaco.

Santo Agostinho, juntamente com Platão e Aristóteles, faz parte da tríade de pensadores fundamentais do pensamento ocidental. O bispo africano teve a capacidade de, com pouco acesso aos escritos dos pensadores anteriores, ser capaz de insights poderosos, que serviram e ainda servem de inspiração para autores de todas as épocas. Entretanto, a reflexão filosófica não era um luxo intelectual para ele. A filosofia foi

\footnotetext{
${ }^{1}$ Doutor em filosofia pela Pontifícia Universidade Católica do Rio Grande do Sul (PUCRS) e professor de filosofia na Escola Superior Dom Helder Câmara (ESDHC). E-mail: mboasr@yahoo.com.br
} 
encarada como capaz de levar o ser humano à plenitude. Em Agostinho, vida e obra se confundem!

O texto apresentado trata de sua compreensão da filosofia como a atividade que leva à felicidade. Para tanto, inicialmente, se vale das páginas biográficas das Confessiones para ilustrar como Agostinho se volta para a filosofia e como a sua compreensão, inicialmente, parte de um pressuposto comum aos pensadores da antiguidade, para, no decorrer de suas reflexões, caminhar para uma nova visão sobre o que ela seja, a partir de sua inserção ao Cristianismo.

Num segundo momento, o texto irá se voltar para o Contra Academicos e o De Beata Vita, obras escritas em seu retiro em Cassicíaco. Será mostrado como Agostinho usa o arcabouço intelectual do pensamento grego e romano para adaptá-lo e superá-lo à luz da revelação cristã, no que tange ao problema do fim do ser humano.

A pesquisa ocorrerá através de metodologia qualitativa, a partir de análise bibliográfica de textos agostinianos, bem como do uso de bibliografia secundária.

\section{Agostinho: o encontro com a filosofia}

Pode-se dizer que Agostinho é um pensador da antiguidade. Nesse sentido, ele está inserido dentro da grande questão da filosofia antiga: o fim (telos $\left.{ }^{2}\right)$ do ser humano, ou seja, aquilo que deve ser desejado por si mesmo. Por outro lado, o telos humano está associado à eudaimonia (beata vita, beatitudo), que, muitas vezes, será traduzido como felicidade. As questões do telos e da eudaimonia estão presentes desde os pré-socráticos, passando por Sócrates (469 a.C. - 399 a.C.) e Platão (428/27 a.C. - 348/47 a.C.), até serem sistematizados por Aristóteles (384 a.C. -322 a.C.) $)^{3}$. Mas tais questões chegaram até Agostinho através do orador romano Cícero (106 a.C. - 43 a.C.).

Cícero ${ }^{4}$ pode ser considerado o autor de língua latina que leva a problemática do telos e da eudaimonia para o mundo latino e aquele que irá fazer com que Agostinho passe a

\footnotetext{
${ }^{2}$ HOLTE, Ragnar. Béatitude et Sagesse: Saint Augustin et le problème de la fin de l'homme dans la philosophie ancienne. Paris. Études Augustiniennes, 1962, p. 12, chama a atenção para um sentido psicológico e cosmológico/metafísico da palavra Telos: "Nous pouvons donc distinguer un sens premier, psychologique: la fin que se propose un sujet voulant et agissant, et un sens dérivé, de portée cosmologique et métaphysique: les événements extérieurs semblent être ordonnés à un fin, exactement comme s'ils étaient causes par un sujet conscient.

${ }^{3}$ Cf. HOLTE, Ragnar. Béatitude et Sagesse: Saint Augustin et le problème de la fin de l'homme dans la philosophie ancienne. Paris. Études Augustiniennes, 1962, p. 16 e SVOBODA, Karel. Ideas sobre la felicidad en las primeras obras de San Agustín. in: AVGVSTINVS. Vol. IV. 1959, p. 195-201, p. 195.

${ }^{4}$ ROBLEDO, Antonio Gomez. Cristianismo y Filosofia en la experiencia Agustiniana. Ciudad de México: Imprenta Universitaria, 1942, p. 23 (grifos no original) esclarece que: El pensamento filosófico de Cicerón
} 
buscar uma vida na filosofia. Ao relembrar o percurso de seus estudos de retórica na obra Confessiones, Agostinho, que estava com 19 anos, faz a seguinte descrição:

Seguindo a ordem usada no ensino de tais estudos, cheguei a um livro de um certo Cícero, cuja linguagem quase todos admiram, embora não o seu passado. Esse livro contém uma exortação sua à filosofia e é chamado Hortensius. (...) E o amor pela sabedoria tem o nome grego filosofia, que essas páginas me iluminaram. ${ }^{5}$

Pode-se dizer que o Hortensius de Cícero foi fundamental para que Agostinho se sentisse atraído pelos estudos filosóficos. A obra, hoje perdida, exorta a filosofia no sentido de que ela é aquilo que pode levar à felicidade. Assim, para grande parte do pensamento antigo a filosofia não era compreendida como uma atividade meramente especulativa, mas um modo de vida que leva ao sumo bem, a felicidade. Quando Agostinho se volta para a filosofia é visando esse fim. Ele passará o restante dos seus dias em busca pela felicidade.

Nas suas Confissões, Agostinho ilustra o percurso que faz em busca da felicidade pelas diferentes filosofias às quais abraçou. $\mathrm{Na}$ mesma época em que lia Cícero, ele se volta para as Escrituras, provavelmente influenciado pelo Cristianismo de sua mãe, Mônica, mas não se sente entusiasmado com elas: "Porém, não pensei então no que estou dizendo agora, quando me voltei neles, pareceram-me indignos de serem comparados com a dignidade dos escritos de Túlio (Cícero)." ${ }^{\circ}$

O retorno de Agostinho às Escrituras era um indício de que a figura de Jesus já era importante para ele antes de sua conversão definitiva ao Cristianismo. A interpretação que faz a respeito de sua adesão ao Maniqueísmo ilustra isso: “Assim, caí em homens delirantes soberbos, excessivamente carnais e tagarelas, em cujas bocas havia laços do demônio e um visco confeccionado de mistura das sílabas do teu nome, de nosso Senhor Jesus Cristo e do nosso Paráclito e consolador, o Espírito Santo.”7

queda compreendido en los siguientes libros: el Hortensius, exhortación a la filosofía en general; las Quaestiones Academicae, exposición de la doctrina a la que el filósofo latino presta su adhesión personal; el De finibus, estudio del supremo bien asi como del más grave mal; el De natura deorum, el De divinatione y el De fato, consagrados especialmente a la religión, y por último, las Quaestionibus Tusculanae.

${ }_{5}^{5}$ Conf. III, 4, 7-8: “(...) et usitato iam discendi ordine perveneram in librum cuiusdam Ciceronis, cuius linguam fere omnes mirantur, pectus non ita. Sed liber ille ipsius exhortationem continet ad philosophiam et vocatur Hortensius. (...) Amor autem sapientiae nomen graecum habet philosophiam, quo me accendebant illae litterae."

${ }^{6}$ Conf. III, V, 9: "Non enim sicut modo loquor, ita sensi, cum attendi ad illam scripturam, sed visa est mihi indigna, quam Tullianae dignitati compararem."

${ }^{7}$ Conf. III, VI, 10: "Itaque incidi in homines superbe delirantes, carnales nimis et loquaces, in quorum ore laquei diaboli et viscum confectum commixtione syllabarum nominis tui et Domini Iesu Christi et Paracleti consolatoris nostri Spiritus Sancti." 
A desilusão com os Maniqueístas e seus costumes extravagantes fará com que Agostinho se volte para o ceticismo, conhecido por ele através dos acadêmicos ${ }^{8}$ : Com efeito, também veio a mim o pensamento de que eram mais prudentes os filósofos que eles chamam de acadêmicos, que sobre todas as coisas duvidavam e que julgavam que nada verdadeiro pode ser entendido pelo homem." . Ainda sobre eles: "Assim, segundo o costume dos acadêmicos, como se acredita, duvidando de todas as coisas e oscilando entre todas, resolvi abandonar os maniqueus, julgando que durante o tempo da minha dúvida não deveria permanecer naquela seita, à qual já preferia alguns filósofos." 10

Nessa época em que abandonou o maniqueísmo e se voltou ao Ceticismo, Agostinho se encontra em Milão e tem a oportunidade de ouvir os sermões de um dos cristãos mais famosos de sua época, o bispo Ambrósio (340-397). Agostinho ouve os sermões do bispo não com o intuito ouvir suas mensagens, mas devido à fama que Ambrósio tinha como orador. Apesar disso, Agostinho fica encantado com a capacidade que Ambrósio tinha de explicar certas passagens bíblicas que antes ele considerava ridículas ${ }^{11}$. Paralelamente, em sua procura pela verdadeira filosofia, Agostinho se volta para a Igreja Católica por costume dos antepassados, sem ainda se considerar um verdadeiro cristão ${ }^{12}$.

A adesão completa ao Cristianismo ainda dependerá do encontro com o que hoje é conhecido como neoplatonismo. Agostinho já vinha se deparando com os argumentos platônicos nos sermões de Ambrósio, mas irá se deparar com tais textos “(...) por meio de um terrível homem inchado de enorme orgulho, certos livros dos platônicos, traduzidos da língua grega para a latina." ${ }^{13}$ Era o encontro de Agostinho com o suprassensível. A incapacidade de Agostinho conceber o suprassensível de maneira intelectual, vinha sendo um empecilho para que ele concebesse algo como Deus sem estar preso a uma concepção

\footnotetext{
${ }^{8}$ BROWN, Peter. Santo Agostinho: Uma Biografia. Rio de Janeiro e São Paulo: Editora Record, 2005, p. 95 esclarece: "Em seus diálogos filosóficos, Cícero tornara disponíveis em latim as concepções céticas da 'Nova Academia'. Essas doutrinas tinham sido elaboradas no séc. II a. C por Carnéades, um admirável lógico grego, em oposição aos estóicos. Os estóicos haviam afirmado que o homem era capaz de conhecer com exatidão a natureza do mundo que o cercava e, desse modo, agir sabiamente e com perfeita certeza, à luz desse conhecimento. Os céticos - chamados de Academici (os Acadêmicos) - haviam negado que o conhecimento pudesse ser conquistado com tamanha facilidade."

${ }^{9}$ Conf. V, X, 19: "Etenim suborta est etiam mihi cogitatio, prudentiores illos ceteris fuisse philosophos, quos Academicos appellant, quod de omnibus dubitandum esse censuerant nec aliquid veri ab homine comprehendi posse decreverant."

${ }^{10}$ Conf. V, XIV, 25: "Itaque Academicorum more, sicut existimantur, dubitans de omnibus atque inter omnia fluctuans Manichaeos quidem relinquendos esse decrevi, non arbitrans eo ipso tempore dubitationis meae in illa secta mihi permanendum esse cui iam nonnullos philosophos praeponebam."

${ }^{11}$ Cf. Conf. V, XIII, 23 e VI, IV, 6.

${ }^{12}$ Cf. Conf. V, XIV, 25.

${ }^{13}$ Conf. VII, IX, 13: “(...) per quemdam hominem immanissimo typho turgidum quosdam Platonicorum libros ex Graeca lingua in Latinam versos (...).”
} 
de mundo materialista. Nesse sentido, o neoplatonismo fora uma corrente filosófica de passagem para o Cristianismo, que Agostinho irá, no fim das contas, conceber como a verdadeira filosofia.

\section{Agostinho: em busca pela Verdadeira Filosofia}

Agostinho, nas Confissões, possibilita a reconstituição biográfica de sua adesão ao Cristianismo, passando por outras correntes de pensamento. No fundo, a sua preocupação era a busca pela felicidade através de uma filosofia que lhe possibilitasse tal alcance. Em 386 ocorreu a conversão total de Agostinho ao Cristianismo, que será batizado por Ambrósio em 24 de abril de 387.

Entre o período da conversão e o batismo, Agostinho passará alguns meses em Cassicíaco, localidade próxima de Milão, na quinta de seu amigo Verecundo ${ }^{14}$ :

En el otonõ de 386 había venido Agustin a Cassiciaco con los propósitos de descansar de su magisterio, fortalecer su salud y prepararse para recibir el Bautismo en la primavera. Vino con su madre Mónica, su amigo Alipio, su hijo Adeodato, su hermano Navigio, sus compatriotas Trigecio y Alipio y sus discípulos Lastidiano y Rústico. Allí y en su compañía escribió los primeiros libros que de él nos han llegado. ${ }^{15} 16$

Os livros escritos em forma de diálogo são Contra Academicos, De Beata Vita, De Ordine e Soliloquia. Há neles uma influência do ambiente vivido naqueles dias em Cassicíaco. Agostinho tem a primeira oportunidade de pensar seriamente o Cristianismo como uma forma de sentido pleno para a vida. Apesar de recém convertido, ele entende o Cristianismo como o que melhor lhe possibilitará responder à questão fundamental colocada pela filosofia: qual o fim do ser humano.

O Diálogo De Beata Vita pode ser compreendido como Agostinho passa a tomar o Cristianismo como sendo a verdadeira filosofia, isto é, aquela que responde a respeito da finalidade do ser humano. O De Beata Vita tem início no dia do aniversário de Agostinho, 13 de novembro, ocasião em que está ocorrendo um banquete e uma confraternização entre os presentes ${ }^{17}$. Agostinho começa a obra com a bela metáfora da vida como sendo uma embarcação em alto mar, em que todos estão lançados nela por Deus, natureza,

\footnotetext{
${ }^{14}$ Cf. Conf. IX, III, 5.

${ }^{15}$ MOLINA, Mario A. Felicidad y sabiduría: Agustín en novembro del 386. in: AVGVSTINVS. Vol. XVIII, 1973 , p. $355-372$, p. 356

${ }^{16}$ Para um estudo a respeito dos personagens presentes em Cassicíaco, ver McNAMARA, Marie Aquinas. Friendship in Saint Augustine. Fribourg: The University Press, 1958.

${ }^{17}$ Cf. De $B V$ I, 6.
} 
necessidade e/ou vontade. ${ }^{18}$ Independentemente de como se chega a alcançá-la, os participantes partirão do pressuposto de que todos querem ser felizes. ${ }^{19}$ Mas quem e em quais contextos chega-se à felicidade?

Agostinho afirma que o ser humano é composto de corpo e alma ${ }^{20}$, sendo a alma a melhor parte. A alma é superior ao corpo, mas ambas necessitam de alimento. A noção de que a alma é superior ao corpo aparece também na obra Contra Academicos, onde Agostinho afirma que a felicidade depende que a melhor parte do ser humano, a alma, domine as demais ${ }^{21}$.

Quem é o ser humano que vive através de sua melhor parte? A reposta de Agostinho é aquela presente no imaginário do pensamento antigo, isto é, o sábio (sapiens). A sutileza do pensamento de Agostinho pode ser notada a partir desse momento, pois ele parte de noções presentes no pensamento antigo, para, a partir delas, formar uma nova visão filosófica.

Ao longo das obras de Cassicíaco, Agostinho irá se debruçar sobre o sábio de diferentes maneiras. No ambiente de crítica ao ceticismo do Contra Academicos, Agostinho e seus companheiros se questionam a respeito da maneira que o sábio é feliz: se pela busca da verdade (veritas), proposta associada à nova academia ${ }^{22}$, representada por Licêncio, ou através da posse efetiva da verdade, noção defendida por Trigécio e Agostinho, que chega a afirmar: "Na verdade, como desejamos ser felizes, seja na descoberta, seja na diligente investigação da verdade, deixando de lado todas as outras coisas, se queremos ser felizes, é necessário procurá-la. ${ }^{23}$ ",

Agostinho, no Livro III do Contra Academicos, vai lidar com a refutação da posição dos acadêmicos, a fim de sustentar a existência da Verdade e da felicidade decorrente de

${ }^{18}$ Cf. De $B V$ I, 1.

${ }^{19}$ Cf. $D e B V$ II, 10.

${ }^{20}$ Cf. De BV II, 7. Para HOLTE, Ragnar. Beatitude et Sagesse: Saint Augustin et le problème de la fin de l'homme dans la philosophie ancienne. Paris: Études Augustiniennes, 1962, p.195, Agostinho parte de uma noção peripatética ao compreender o ser humano composto de corpo e alma. SVOBODA, Karel. Ideas sobre la felicidad en las primeras obras de San Agustín. in: AVGVSTINVS. Vol. IV. 1959, p. 195-201, p. 197, diz que “(...) al tratar del bien supremo, Cicerón y Varrón habían hecho la misma afirmación (...).

${ }^{21}$ Cf. C. Ac. I, $2,5$.

${ }^{22}$ BROWN, Peter. Santo Agostinho: Uma Biografia. Rio de Janeiro e São Paulo: Editora Record, 2005, p. 95 esclarece a respeito da Nova Academia: "Em seus diálogos filosóficos, Cícero tornara disponíveis em latim as concepções céticas da 'Nova Academia'. Essas doutrinas tinham sido elaboradas no séc. II a. C pelo acadêmico Carnéades, um admirável lógico grego, em oposição aos estóicos (sic). Os estóicos (sic) haviam afirmado que o homem era capaz de conhecer com exatidão a natureza do mundo que o cercava $\mathrm{e}$, desse modo, agir sabiamente e com perfeita certeza, à luz desse conhecimento. Os céticos - chamados de Academici, 'os acadêmicos' - haviam negado que o conhecimento pudesse ser conquistado com tamanha facilidade".

${ }^{23}$ C. Ac. I, 9, 25. "Nam cum beati esse cupiamus, sive id fieri non potest nisi inventa, sive non nisi diligenter quaesita veritate; postpositis caeteris omnibus rebus, nobis, si beati esse volumus, perquirenda est". 
sua posse. Sua própria conversão ao Cristianismo, meses antes, vai ao encontro dessa perspectiva. Assim, para ele, o sábio, aquele que detém a verdade, também possui a sabedoria (sapientia $)^{24}$, conceito que será melhor trabalhado no De Beata Vita.

O assunto sobre a figura do sábio volta a ser discutida, e, para sua definição, os participantes resolvem analisar a figura contrária a ele, o ignorante (stultus). Sábio será definido como possuidor de uma alma mais plena e livre do que o ignorante. A fim de ilustrar um pouco mais tais definições, inicia-se uma análise de Agostinho a respeito de palavras que estariam associadas às noções propostas. Por um lado, os ignorantes teriam o vício malignidade (nequitia), o maior de todos eles, e que deriva da palavra nihil, nada, por outro, o sábio possui virtude (virtu) e seus sinônimos temperança e frugalidade (frugalitas), palavra oriunda do latim fruges, que significa frutos. Dessa forma, sábio é aquele que possui uma alma fecunda, ao contrário do ignorante, que tem uma alma improdutiva. $^{25}$

Retomando uma perspectiva comum ao pensamento antigo, pode-se definir o sábio para Agostinho como virtuoso e o ignorante vicioso. Para ele, a alma do sábio é perfeita, pois nada lhe falta, sendo que ele, se possuir determinados bens ele os utilizará, mas as suas faltas não acarretam desânimo, agindo baseado nas virtudes e na divina lei da sabedoria (divina lege sapientiae), bens que não podem ser retirados sem seu querer. ${ }^{26}$

Agostinho estaria baseado em definições estoicas, neoplatônicas e epicuristas a respeito do sábio, que, por meio de sua beatitude, é capaz de superar quaisquer sofrimentos corporais e faltas materiais ${ }^{27}$. Agostinho dialoga constantemente com os filósofos antigos.

Portanto, assim como diziam os estoicos ${ }^{28}$, a felicidade, para Agostinho, advém da posse da virtude, fazendo com que o sábio não dependa de outros bens para alcança-la.

\footnotetext{
${ }^{24}$ Cf. C. Ac. III, 3, 5.

${ }^{25}$ Gf. De $B V$ II, 8.

${ }^{26}$ Cf. De $B V$ IV, 25

${ }^{27}$ Cf. HOLTE, Ragnar. Beatitude et Sagesse: Saint Augustin et le problème de la fin de l'homme dans la philosophie ancienne. Paris: Études Augustiniennes, 1962, p.197, nota 3 e LEJARD, Françoise. El tema de la felicidad em los diálogos de san Agustin In: AUGUSTINUS. Vol. 20, 1975, 29-82, p. 40.

${ }^{28}$ Em REALE, Giovanni, História da Filosofia Antiga III: Os sistemas da era helenística. Trad. Marcelo Perini. São Paulo: Editora Loyola, 1998, p. 339 há a seguinte citação de Estobeu, Anthol., II, 77, 16 (= von Arnim, S.V.F., III, fr. 16): "Dizem (os estóicos) que o fim é ser feliz, pelo qual fazemos todas as coisas, enquanto ele não é feito por nenhuma coisa. Ele consiste em viver segundo a virtude, em viver de acordo com a natureza e, ainda, o que é o mesmo, em viver segundo a natureza. Zenão definiu a felicidade desse modo: a felicidade é um próspero curso de vida. Também Cleanto, nos seus escritos, serve-se dessa definição, assim como Crísipo e todos os seus seguidores, afirmando que a felicidade é o fim, enquanto fim é ter felicidade, o que equivale a ser feliz. Segue-se daí que são equivalentes 'viver segundo a natureza', 'viver nobremente', 'viver bem' e, ainda, 'bondade e nobreza', 'virtude e o que participa da virtude'. É
} 
Entretanto, a aproximação com os estoicos é um passo para uma visão própria e distinta de Agostinho sobre a felicidade e, consequentemente, sobre a filosofia.

O sábio é feliz e o estulto, por sua vez, é miserável, infeliz. (miser). Assim, pode-se afirmar que o sábio é virtuoso, feliz e que tem uma alma frutífera, e que o ignorante é infeliz, vicioso e tem uma alma vazia (sem frutos). Possuir a alma frutífera significa que a alma está preenchida com seu alimento, isto é, a sabedoria (sapientia). A alma vazia, por sua vez, é alma indigente, carente (egestas), por isso, infeliz.

Nesse momento do diálogo, a mãe de Agostinho, Mônica, relembra o exemplo de uma personagem importante no imaginário antigo, Orata $^{29}$, que, apesar de possuir bens materiais em demasia, permanecia com a alma indigente (animi egestas), portanto, infeliz. ${ }^{30}$ Nesse caso, a plenitude (plenitudo) da alma será apresentada como contrária a uma alma indigência, portanto, afirmar que uma alma possui plenitude é o mesmo que dizer que possui sabedoria, frugalidade, temperança e virtude. ${ }^{31}$

De posse dessas definições, Agostinho justificará a relação entre os termos apresentados. O termo frugalitas ${ }^{32}$ é tomado como sinônimo de temperança (temperantia), que advém da palavra temperias, que pode ser traduzido como proporção. Frugalitas também é sinônimo modestia, isto é, moderação, palavra que se origina do termo modus, medida ${ }^{33}$. Dessa maneira, Agostinho esclarece que a plenitude da alma está em ser moderada e temperante, e isso significa possuir sabedoria. A posse da sabedoria faz com que a alma moderada não busque os bens materiais demasiadamente, e não sofra com suas perdas, assim como faz com que ela evite paixões, como o orgulho. ${ }^{34}$

De certa forma, Agostinho, até aqui, acompanha o entendimento da filosofia dos antigos na relação que ela faz entre sabedoria, medida e felicidade. Mas aquela busca pela

também evidente que é bom tudo o que é virtuoso e que é mau tudo o que é vicioso. Por isso também o fim dos estoicos equivale a uma vida segundo a virtude".

${ }^{29}$ OROZ-RETA, José, Sêneca y San Agustín. Influencia o coicidencia? In: AUGUSTINUS. V. 10, 1965, p. 295-309, p.307, afirma ser Sergio Orata um exemplo mítico para a antiguidade, símbolo de riqueza e felicidade.

${ }^{30} \mathrm{Cf}$. De $B V \mathrm{IV}, 28$.

${ }^{31}$ Cf. De BV IV, 30.

${ }^{32}$ Para LEJARD, Françoise. El tema de la felicidad em los diálogos de san Agustin In: AUGUSTINUS. Vol. 20, 1975, 29-82, p. 64 afirma que Agostinho retoma o termo frugalitas de Cícero.

${ }^{33}$ Cf. De BV IV, 32. Sobre o termo modus esclarece LEJARD, Françoise. El tema de la felicidad em los diálogos de san Agustín In: AUGUSTINUS. Vol. 20, 1975, 29-82, p. 64: "Los epícureos, estóicos y pitagóricos subrayan la importancia de la mesura. Aristóteles define la virtud como el 'justo medio entre dos extremos'. Platon llama mesura, 'metron' a la idea de las ideas. Plotino e Ciceron le atribuyen tambien una gran importancia".

${ }^{34}$ Cf. De BVIV, 33. 
sabedoria, ideal do pensamento anterior, assimilado por Agostinho, passa a ter outro significado para ele.

Agostinho afirma que para ser feliz (beatus) é necessário a posse de um bem permenente, que não pode ser perdido pelo acaso, como acontecera com Orata. O único bem eterno e imutável é Deus. Assim, para ser feliz é preciso possuir a Deus (Deum habere $)^{35}$.

No diálogo com seus interlocutores, Agostinho quer saber quem, afinal, possui Deus. Para Licêncio, é quem vive bem; para Trigésio, quem faz o que Deus quer, e, para Adeodato $^{36}$, quem não tem um espírito (spiritus) imundo, isto é, aquele que vive castamente, com os olhos voltados para Deus, sem se perder em outros seres. Agostinho aproveita as três respostas para levar adiante ser raciocínio. Para ele, quem vive bem faz a vontade de Deus e não possui um espírito impuro. ${ }^{37}$ Assim, afirma serem a mesma coisa. Mônica ainda complementa com a noção de que Deus está em todos ${ }^{38}$, por isso, quem o possui o tem benévolo.

É possível sintetizar o percurso feito. O ser humano feliz (beatus) está associado à figura do sábio (sapiens), possuidor da virtude (virtus). Sábio é aquele que procura e descobre a verdade (veritas). Com isso, possui sabedoria (sapientia), que é sinônimo de plenitude (plenitudo) e moderação do espírito (modus animi). Esses três conceitos, por sua vez, significam possuir Deus, bem eterno e imutável. Dessa maneira, sábio é aquele que possui Deus, e, por isso é feliz. Com a associação da felicidade a Deus, Agostinho pensa a filosofia em uma nova perspectiva.

Apesar de recém convertido, Agostinho já pensa Deus a partir da fé cristã, por isso, quando fala em Deus, está pensando em Deus Uno-Trino: Pai, Filho e Espírito Santo, identificando-os, respectivamente, com a Suma Medida, a Verdade (Sabedoria) e o Espírito que relaciona Medida e Verdade.

${ }^{35}$ Cf. De BV II, 11. HOLTE, Ragnar. Beatitude et Sagesse: Saint Augustin et le problème de la fin de l'homme dans la philosophie ancienne. Paris: Études Augustiniennes, 1962, p.216-217 sugere que a posse de Deus (Deum habere) deve ser interpretada como uma participação (participatio) em Deus.

${ }^{36}$ Filho de Agostinho.

${ }^{37} \mathrm{Cf}$. De $B V$ III, 18 .

${ }^{38}$ De BV III, 21. O'CONNELL R. J Ennead VI, 4 and 5 in the Works of Saint Augustine. In: Revue des Études Augustiniennes Vol. 9, 1963, p. 01-39 demonstra a importância dos textos de Plotino (Enéadas VI, 4-5) para Agostinho que tratam da onipresença divina e que fora uma questão permanente no seu pensamento, principalmente, dos Diálogos de Cassicíaco até as Confissões. Na pág 6 afirma: “[...] everyone 'has' God, i. e participates in Him; hence God is present in all criatures, even to those who choose absence from Him through sin. Flee though man may, God remains present, with an angry presence now, but present: for omnipresence is the heart of all participation. From Cassiciacum onwards, Augustine is struck by these paradoxes of omnipresence, but his fascination with the theme is never more evident than in the Confessions" 
O que é a sabedoria digna desse nome, senão a sabedoria de Deus? Aceitamos pela autoridade divina que o Filho de Deus é a Sabedoria de Deus; e, certamente, o Filho de Deus é Deus. Portanto, o feliz possui Deus, como todos já concordamos anteriormente, quando começamos nosso convívio. Mas o que consideras ser a Sabedoria, senão a Verdade? Também isso está dito: Eu sou a verdade. A Verdade que assim existe é por causa da medida suprema, da qual procede e para a qual converte-se inteiramente. E nenhuma outra medida é uma Suma Medida: se nenhuma outra medida é a mais elevada do que a Suprema Medida, é por si mesma Medida. Mas é também necessário que a Suprema Medida seja Verdadeira Medida. Como, portanto, a Verdade é originada pela Medida, assim também se conhece a medida pela Verdade. Pois, nem existiu a Verdade sem Medida, nem a Medida sem a Verdade. Quem é o filho de Deus? Está escrito: a Verdade. Quem é que não tem Pai, senão a Suma Medida? Quem quer que seja, portanto, que chega à Suprema Medida pela Verdade é feliz. Isso é possuir Deus para a alma, isso é gozar de Deus. As outras coisas, embora Deus as possua, não possuem Deus. ${ }^{39}$

O trecho anterior ilustra a importância da autoridade e ajuda divina, já nos diálogos de Cassicíaco, no que diz respeito à felicidade. Em várias passagens dos diálogos, Agostinho fala da autoridade divina como sendo um dos meios, ao lado da razão, para se alcançar a verdade, e, portanto, a felicidade. O final do De Beata Vita é paradigmático nesse sentido. Por sua vez, no Contra Academicos Agostinho afirma que se não fosse o Sumo Deus ter encarnado e estimulando as almas com seus preceitos e exemplos, os homens não teriam voltado os olhos para a pátria:

Esta não é a filosofia deste mundo, que nossos (textos) sagrados justamente detestam, mas do outro (mundo) inteligível, cujas almas cegadas pela escuridão multiforme do erro, e esquecidas sob as profundas sordidezes corporais, a não ser que o Sumo Deus, por clemência ao povo, declinasse e submetesse até o mesmo corpo humano a autoridade do Intelecto divino, de modo que, as almas estimuladas, não somente com os preceitos, mas também com os fatos, poderiam voltar a si mesmas e voltar-se para à pátria, sem lutas de disputas. ${ }^{40}$

Os trechos referidos do De Beata Vita e do Contra Academicos são exemplos da importância da encarnação divina para nortear a vida dos homens para a Verdade suprema, a verdadeira sabedoria e a verdadeira felicidade.

\footnotetext{
${ }^{39}$ De $B V I V$, 34. "Quae est autem dicenda sapientia, nisi quae Dei Sapientia est? Accepimus autem etiam auctoritate divina, Dei Filium nihil esse aliud quam Dei Sapientiam (I Cor I, 24): et est Dei Filius profecto Deus. Deum habet igitur quisquis beatus est: quod omnibus nobis iam ante placuit, cum hoc convivium ingressi sumus. Sed quid putatis esse sapientiam, nisi veritatem? Etiam hoc enim dictum est: Ego sum Veritas (Jo 14, 6). Veritas autem ut sit, fit per aliquem summum modum, a quo procedit, et in quem se perfecta convertit. Ipsi autem summo modo nullus alius modus imponitur: si enim summus modus per summum modum modus est, per seipsum modus est. Sed etiam summus modus necesse est ut verus modus sit. Ut igitur veritas modo gignitur, ita modus veritate cognoscitur. Neque igitur veritas sine modo, neque modus sine veritate unquam fuit. Quis est Dei Filius? Dictum est: Veritas. Quis est qui non habet patrem, quis alius quam summus modus? Quisquis igitur ad summum modum per veritatem venerit, beatus est. Hoc est animo Deum habere, id est Deo perfrui. Caetera enim quamvis a Deo habeantur, non habent Deum"

${ }^{40}$ C.Ac. III, 19, 42: Non enim est ista huius mundi philosophia, quam sacra nostra meritissime detestantur, sed alterius intellegibilis; cui animas multiformibus erroris tenebris caecatas, et altissimis a corpore sordibus oblitas, nunquam ista ratio subtilissima revocaret, nisi summus Deus populari quadam clementia divini intellectus auctoritatem usque ad ipsum corpus humanum declinaret, atque submitteret; cuius non solum praeceptis, sed etiam factis excitatae animae redire in semetipsas, et resipiscere patriam, etiam sine disputationum concertatione potuissent.
} 
A respeito do trecho do Contra Academicos, Holte, seguindo a interpretação de O’Meara, apreende três argumentos a respeito da especulação teleológica: 1- O telos humano, a descoberta da verdade, é o retorno ao mundo inteligível (pátria); 2- O ser humano não é capaz de chegar àquele fim por meio de sua própria razão; 3 - O logos de faz carne para, através, de sua mensagem e obra, conduzir os humanos ao telos. Em suma, Cristo é o ser divino que mostra a verdade aos seres humanos. ${ }^{41}$

Ao recordar nas Confissões seu encontro definitivo com o Cristianismo, Agostinho relata que até chegaste a encontrar nos livros platônicos "no princípio era o Verbo e o Verbo estava com Deus e o Verbo era Deus", dentre outras informações, com outras palavras. Entretanto, que o "verbo se fez carne", que seu nome era Jesus, que se esvaziou de si mesmo, que foi morto e crucificado, e que ressuscitou e está na Glória do Pai, isso ele veio saber posteriormente através da revelação ${ }^{42}$.

Tanto nas obras de Cassicíaco como nas Confissões, Agostinho entende que a filosofia que aprendera a admirar com o Hortensius é limitada para atingir a felicidade. A filosofia humana vai até certo ponto, sendo, pois, necessária a revelação, escancarada pela encarnação de Cristo, para guiar a humanidade para a verdadeira felicidade. Nesse sentido, Agostinho continua a tomar a filosofia como aquilo que leva ao fim do ser humano, mas a compreende como algo distinto dos pensadores gregos e romanos.

Deve-se ressaltar que, nas suas Retratações (Retractaciones), Agostinho lerá suas obras de recém-convertido de maneira bastante crítica. Sobre o De Beata Vita, diz que lhe desagrada a percepção de que o sábio, por esforço próprio, seria capaz de atingir a felicidade nesta vida. ${ }^{43}$ Entre Cassicíaco e as Retractationes há quase 40 anos de conversão e reflexões constantes sobre o Cristianismo. As noções de que a felicidade não depende inteiramente do esforço humano e de que ela não pode ser alcançada neste mundo, farão parte do pensamento agostiniano posterior. Mas, o fato do Agostinho posterior à Cassicíaco deixar de lado tais perspectivas, não significa o abandono da noção de que a filosofia seja o caminho para a felicidade. Filosofia essa compreendida como sendo dependente da Revelação Cristã.

${ }^{41}$ Cf. HOLTE, Ragnar. Beatitude et Sagesse: Saint Augustin et le problème de la fin de l'homme dans la philosophie ancienne. Paris: Études Augustiniennes, 1962, p.95-96.

${ }^{42}$ Cf. Conf. VII, IX, 13-14.

${ }^{43}$ Cf. Retract. I, 2. 


\section{Conclusão}

Agostinho não era um filósofo de profissão, nem um acadêmico. A filosofia entrou em sua vida como uma forma de viver. A leitura do Hortensius de Cícero mostrou para ele, assim como para inúmeros indivíduos da antiguidade, que a filosofia elevava a vida humana para outro patamar. Agostinho narra de forma poética seu encontro com a obra aos 19 anos e sua tentativa desesperada de alcançar o fim humano: a felicidade. A passagem por diferentes visões sobre a vida, tais como o maniqueísmo, o ceticismo e o neoplatonismo, deve ser vista como uma forma de chegar a tão desejada felicidade.

Sua realização existencial, entretanto, ocorrerá do seu encontro com o Cristianismo. Para Agostinho, a religião Cristã pode ser pensada como um modo de viver para se atingir a felicidade, fim último humano. Sendo um dos precursores intelectuais do Cristianismo, como os demais pensadores patrísticos, Agostinho procura refletir a religião Cristã através do arcabouço teórico filosófico. Por isso, ele é um dos fundadores do Ocidente.

Nesse sentido, Agostinho tem a hercúlea tarefa de pensar uma filosofia que se chamará futuramente de Cristã. O problema do fim do ser humano é a grande questão da antiguidade, e Agostinho parte desse problema e do linguajar filosófico disponível para compreender o Cristianismo como sendo a resposta definitiva da existência humana, por isso, também uma certa filosofia. Agostinho compreende o limite da razão humana para responder às questões fundamentais, assim, toma a revelação Cristã como um norte.

As obras escritas após sua conversão, em 386, retratam a maneira como um recente cristão reinterpreta a filosofia antiga à luz da revelação Cristã. Agostinho, como os antigos, pressupõe que a filosofia explicita a resposta para a existência humana. Pressupõe também que o sábio, aquele que detém a sabedoria, a verdade e a medida é feliz. Tudo isso ele aprendeu com a filosofia anterior. Mas, que essas características estão associadas à figura de Cristo, o próprio Deus encarnado, isso ele ressignificou a partir da revelação. A filosofia continuaria a ser tomada por Agostinho como um norte para a vida humana, mas, agora, como filosofia Cristã.

Agostinho até abandonará, com o tempo, a noção de que a felicidade pudesse ser possuída neste mundo, mas jamais deixará de associá-la a Deus, princípio e fim último dos seres humanos. 


\section{Referências}

AURELLI AUGUSTINI. Confessionum libri XIII. In col. "Sancti Aurelii Augustini Opera Omnia", editio latina, Patrologia Latina 32. Disponível em:

http://www.augustinus.it/latino/confessioni/index.htm

AURELLI AUGUSTINI. Contra Academicos libri tres. In col. "S. Aurelii Augustini Opera Omnia", editio latina, Patrologia Latina, 32. Disponível em:

http://www.augustinus.it/latino/contr_acc/index.htm

AURELLI AUGUSTINI. De Beata Vita liber unus. In: col. S. Aurelii Augustini Opera Ominia- editio latina, Patrologia Latina 32. Disponível em:

http://www.augustinus.it/latino/felicita/index.htm.

AURELLI AUGUSTINI. Retractationum libri duo, In col. "S. Aurelii Augustini Opera Omnia", editio latina, Patrologia Latina 32. Disponível em http://www.augustinus.it/latino/ritrattazioni/index.htm

BROWN, Peter. Santo Agostinho: Uma Biografia. Rio de Janeiro e São Paulo: Record, 2005.

HOLTE, Ragnar. Béatitude et Sagesse: Saint Augustin et le problème de la fin de l'homme dans la philosophie ancienne. Paris: Études Augustiniennes, 1962.

LEJARD, Françoise. El tema de la felicidad em los diálogos de san Agustín In: AVGVSTINVS. Vol. 20, 1975, 29-82.

McNAMARA, Marie Aquinas. Friendship in Saint Augustine. Fribourg: The University Press, 1958.

MOLINA, Mario A. Felicidad y sabiduría: Agustín en novembro del 386. In: AVGVSTINVS. Vol. XVIII, 1973, p. 355-372.

O'CONNELL R. J Ennead VI, 4 and 5 in the Works of Saint Augustine. In: Revue des Études Augustiniennes Vol. 9, 1963, p. 01-39.

OROZ-RETA, José. Sêneca y San Agustín. Influencia o coicidencia? In: AVGVSTINVS. V. 10, 1965, p. 295-309.

REALE, Giovanni. História da Filosofia Antiga III: Os sistemas da era helenística. São Paulo: Loyola, 1998.

ROBLEDO, Antonio Gomez. Cristianismo y Filosofia en la experiencia Agustiniana. Ciudad de México: Imprenta Universitaria, 1942.

SANTO AGOSTINHO. Confissões. São Paulo: Companhia das Letras, 2017, p. 64 [ebook]. 
SVOBODA, Karel. Ideas sobre la felicidad en las primeras obras de San Agustín. in: AVGVSTINVS. Vol. IV. 1959, p. 195-201. 